Journal of Fundamental and Applied Sciences

ISSN 1112-9867

Available online at

http://www.jfas.info

\title{
CORROSION INHIBITION BEHAVIOR OF KETOSULFONE FOR ZINC IN ACIDIC MEDIUM
}

\author{
Narayana Hebbar ${ }^{1}$, B. M. Praveen ${ }^{2 *}$, B. M. Prasanna ${ }^{3}$, T. Venkatarangaiah Venkatesha ${ }^{4}$. \\ ${ }^{1}$ Department of Chemistry, Bearys Institute of Technology, Mangalore, India. \\ ${ }^{2}$ Department of Chemistry, Srinivas School of Engineering, Mukka, Mangalore, India, \\ ${ }^{3}$ Department of Chemistry, Shree Tharalabalu Jagdgru Institute of Technology, Ranebennur, \\ Haveri, Karnataka, India. \\ ${ }^{4}$ Department of Studies in Chemistry, School of Chemical Sciences, Kuvempu University, \\ Shankaraghatta, Karnataka, India.
}

Received: 22 February 2015/ Accepted: 25 May 2015/ Published online: 31 March 2015

\begin{abstract}
The corrosion inhibition behavior of Ketosulfone for zinc is investigated by polarization and AC-impedance techniques at $303-333 \mathrm{~K}$. The Tafel plots indicates that the Ketosulfone is a mixed type inhibitor. The interaction between metal and inhibitor is explained by Langmuir adsorption isotherm. $\Delta \mathrm{G}_{\text {ads }}^{0}$ and $\Delta \mathrm{H}^{0}$ ads value indicates the electrostatic interactions between metal and inhibitor. Calculated activation parameters explains the corrosion process. SEM images show the difference between inhibited solutions and blank solution.
\end{abstract}

Key words: corrosion inhibitor; adsorption; Langmuir isotherm; Zinc.

\section{INTRODUCTION}

Zinc is a very important metal in the industry and domestic purposes and it is extensively used for galvanization process.

Author Correspondence, e-mail: na.hebbar1@gmail.com

ICID: 1145327 
Under aggressive conditions, zinc metal undergoes corrosion which gives the white colored rust [1-3]. The protection of metal from the corrosion is necessary in an acidic medium and alkaline medium. By using organic compounds, we can achieve protection of metals against corrosion. Compounds containing sulfur and nitrogen can be used for the corrosion inhibition of zinc in acid or nearly alkaline medium. The increase in the hydrogen overvoltage on the corroding metal is due to the presence of organic compounds [4-6]. Recently, the new type of corrosion inhibitors is developed to achieve the environmental regulations on industrial consumption and development thus, natural products, pharmaceutical ingredients and environment-friendly products, have gained much attention in regard to the development of green corrosion inhibitors that have high inhibition efficiency $[7,8]$. The drug ketosulfone is a very good corrosion inhibitor for the mild steel [9].

In the present work, the inhibiting action of ketosulfone for zinc in $0.1 \mathrm{M} \mathrm{HCl}$ has been done by various methods.

Ketosulfone is an anti-inflammatory drug. The presence of electron rich nitrogen, oxygen, sulfur atoms, and $\pi$ - bonds in its structure are in favor of its adsorption on the metal surface, which gives scope to its study as a potential corrosion inhibitor.

The compound ketosulfone was purchased from Ramdev Chemicals India Pvt., Ltd., and Mumbai. IUPAC name of the ketosulfone is 1-(6-methylpyridine-3-yl) -2 (4-methylsulphonyl) phenyl ethanone. The structure of the molecule is as shown in Figure1.<smiles>COS(=O)(=O)c1ccc(CC(=O)c2ccc(C)nc2)cc1</smiles>

Fig 1. Structure of 1-(6-methylpyridine-3-yl)-2(4-methylsulphonyl) phenyl ethanone (ketosulfone)

\section{RESULTS AND DISCUSSION}

Tafel Polarization measurements: 


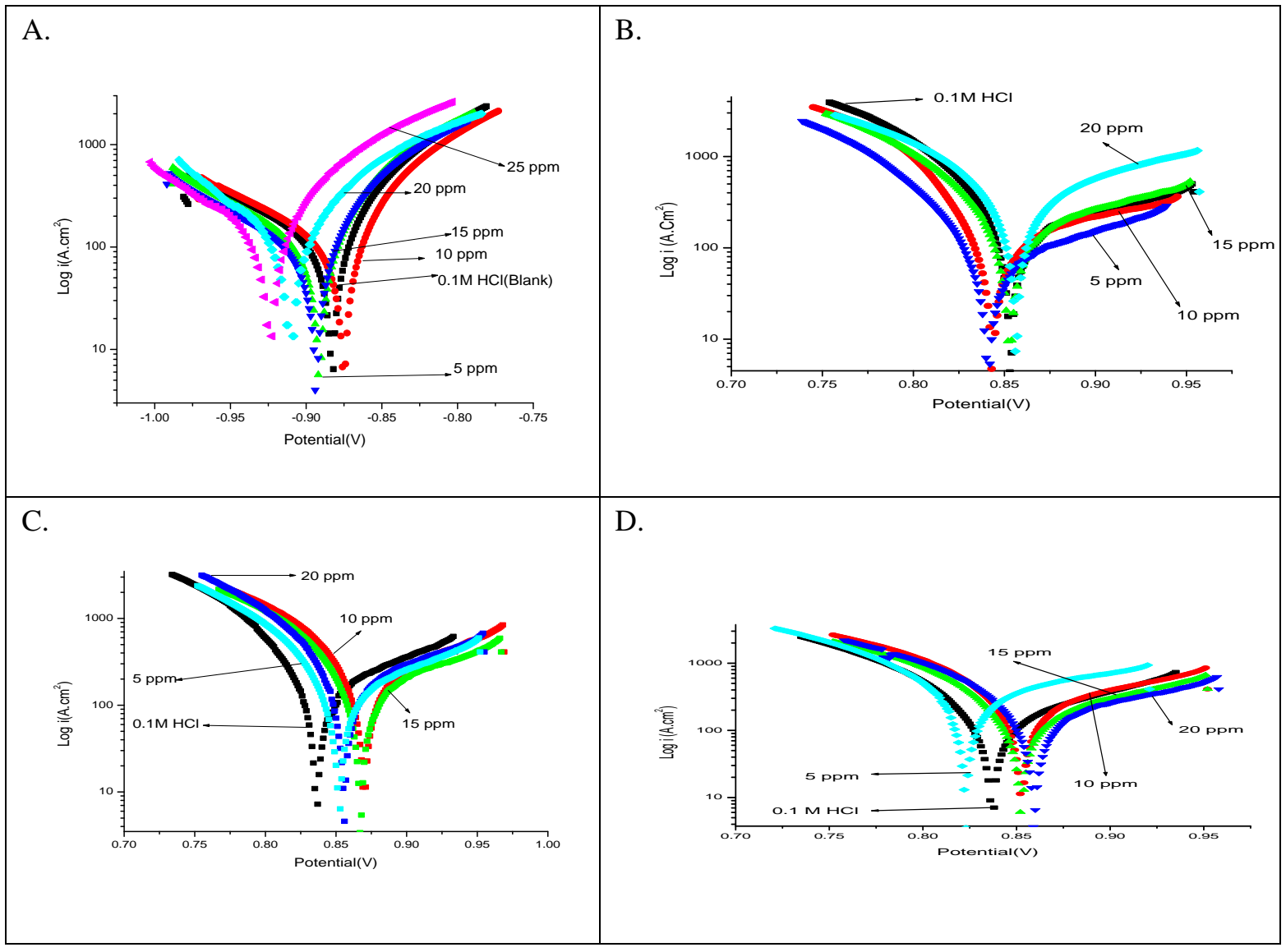

Fig.2. Tafel Plots for zinc in $0.1 \mathrm{M} \mathrm{HCl}$ in the absence and presence of different Inhibitor concentrations at (A) $303 \mathrm{~K}$ (B) $313 \mathrm{~K}$ (C) $323 \mathrm{~K}$ (D) $313 \mathrm{~K}$ temperatures.

The absolute corrosion rate can be measured by the electrochemical technique of polarization resistance and it is expressed in Milli-inches per year (mpy). Polarization resistance is also called as "linear polarization" [11].

The obtained Tafel plots are as shown in Figure 2. The electrochemical corrosion kinetic parameters such as corrosion potential $\left(\mathrm{E}_{\mathrm{corr}}\right)$, corrosion current density ( $\left.\mathrm{i}_{\text {corr }}\right)$, cathodic Tafel slope $\left(\beta_{\mathrm{c}}\right)$, anodic Tafel slope $\left(\beta_{\mathrm{a}}\right)$ and inhibition efficiency $\left(\eta_{\mathrm{p}}\right)$ are reported in Table 1 .

The corrosion current can be related directly to the corrosion rate through the following equation [12].

$$
\text { Corrosion Rate }(m p y)=\frac{0.13 \times i_{\text {corr }} \times E . W .}{d}
$$


Where, E.W. = equivalent weight of the corroding species, $\mathrm{d}=$ density of the corroding species.

The anodic or cathodic Tafel plots are described by the Tafel equation [13]:

$$
\eta=\frac{\beta \log i}{i_{\text {corr }}}
$$

$\eta=$ overvoltage, the difference between the potential of the specimen and the corrosion potential.

$\beta=$ Tafel constant.

The inhibition efficiency $\left(\eta_{\mathrm{p}}\right)$ was calculated from following relation

$$
\eta_{\mathrm{P}}=\frac{\mathrm{i}_{\text {corr }}^{\mathrm{o}}-\mathrm{i}_{\text {corr }}}{\mathrm{i}_{\text {corr }}^{\mathrm{o}}} \times 100
$$

Where, $\mathrm{i}_{\text {corr }}$ and $\mathrm{i}_{\text {corr }}$ are corrosion current in the absence and presence of inhibitor, respectively.

A potentiodynamic polarization plot, such can yield important information such as:

- The Tafel extrapolation method is very accurate which is equal or greater than conventional weight loss methods.

- It is possible to measure extremely low corrosion rates by using potentiodynamic polarization plots.

- A direct measure of the corrosion current can be provided by Tafel plots. As expected, As the increase in the concentration of inhibitor, The rate of corrosion was inhibited. The addition of the inhibitor which reduces the anodic reaction and also retards the cathodic reaction [14].

According to many literatures $[15,16]$ the compound can be classified as an anodic or cathodic inhibitor, when the potential displacement is at least $85 \mathrm{mV}$ with respect to the blank solution. In the present study the tafel plots indicate that the inhibitors are mixed type inhibitor. 
Table 1. Tafel and AC impedance results for the corrosion of zinc in presence of different Concentration of Ketosulfone in $0.1 \mathrm{M} \mathrm{HCl}$.

\begin{tabular}{|c|c|c|c|c|c|c|c|c|c|c|}
\hline $\begin{array}{l}\text { Temp. } \\
\text { (K) }\end{array}$ & $\begin{array}{c}\text { Inhibitor } \\
\text { con }^{n} \\
(\mathbf{p p m})\end{array}$ & $\begin{array}{l}\text { Ecorr } \\
(\mathbf{V})\end{array}$ & $\begin{array}{c}\mathbf{i}_{\text {corr }} \\
\mathbf{m A} \\
\mathbf{c m}^{-2}\end{array}$ & $\begin{array}{c}\text { Corrosion } \\
\text { Rate (mpy) }\end{array}$ & $\begin{array}{c}\beta c \\
\text { mV/decade }\end{array}$ & $\begin{array}{c}\boldsymbol{\beta a} \\
\text { mV/decade }\end{array}$ & $\begin{array}{l}\eta_{p} \\
(\%)\end{array}$ & $\begin{array}{l}R_{p} \\
\mathbf{c m}^{2}\end{array}$ & $\begin{array}{c}C_{d l} \\
(\mu F \\
\left.\mathbf{c m}^{-2}\right)\end{array}$ & $\begin{array}{l}\eta_{\mathrm{z}} \\
(\%)\end{array}$ \\
\hline \multirow{5}{*}{303} & Blank & -0.879 & 16.3 & 1.903 & 7.315 & 8.399 & - & 72.57 & 0.047 & - \\
\hline & 5 & -0.890 & 14.7 & 1.715 & 7.773 & 9.019 & 9.8 & 85.12 & 0.039 & 14.7 \\
\hline & 10 & -0.875 & 12.3 & 1.404 & 8.621 & 11.278 & 24.60 & 92.55 & 0.031 & 21.55 \\
\hline & 15 & -0.898 & 10.4 & 1.325 & 8.645 & 11.400 & 36.1 & 125.41 & 0.015 & 42.1 \\
\hline & 20 & -0.920 & 8.67 & 1.010 & 5.055 & 5.456 & 59.09 & 152.8 & 0.010 & 52.5 \\
\hline
\end{tabular}

$\begin{array}{ccccccccccc} & \text { Blank } & -0.862 & 25.7 & 2.07 & 7.609 & 8.668 & - & 55.87 & 0.068 & - \\ & 5 & -0.846 & 22.3 & 1.87 & 8.011 & 9.257 & \mathbf{1 3 . 2} & 65.67 & 0.061 & \mathbf{1 4 . 9 2} \\ & 10 & -0.851 & 16.5 & 1.65 & 6.028 & 6.442 & \mathbf{3 5 . 7} & 87.59 & 0.049 & \mathbf{3 6 . 2 0} \\ \mathbf{3 1 3} & 15 & -0.854 & 14.8 & 1.41 & 7.605 & 9.136 & \mathbf{4 2 . 4} & 96.6 & 0.035 & \mathbf{4 2 . 1 6} \\ & 20 & -0.859 & 13.9 & 1.12 & 7.868 & 9.650 & \mathbf{4 5 . 9} & 106.7 & 0.024 & \mathbf{4 7 . 6}\end{array}$

$\begin{array}{cccccccccc}\text { Blank } & -0.839 & 29.2 & 2.60 & 8.309 & 11.480 & - & 61.11 & 0.072 & - \\ 5 & -0.851 & 25.8 & 2.37 & 8.157 & 9.869 & \mathbf{1 1 . 6} & 71.08 & 0.059 & \mathbf{1 4 . 0} \\ 10 & -0.866 & 22.9 & 2.05 & 8.099 & 9.543 & & 75.34 & 0.051 & \mathbf{1 8 . 8} \\ & & & & & & \mathbf{2 1 . 5} & & & \\ 15 & -0.871 & 21.1 & 1.93 & 8.286 & 10.002 & \mathbf{2 7 . 7} & 79.9 & 0.044 & \mathbf{2 3 . 5} \\ 20 & -0.852 & 19.9 & 1.86 & 7.235 & 3.873 & \mathbf{3 1 . 8} & 90.5 & 0.041 & \mathbf{3 2 . 4}\end{array}$

$\begin{array}{ccccccccccc} & \text { Blank } & -0.841 & 32.8 & 2.95 & 7.565 & 10.113 & - & 50.40 & 0.081 & - \\ & 5 & -0.835 & 29.1 & 2.80 & 7.374 & 8.432 & \mathbf{1 1 . 2} & 54.98 & 0.057 & \mathbf{8 . 3 0} \\ & 10 & -0.851 & 26.8 & 2.45 & 8.244 & 9.605 & \mathbf{1 8 . 2} & 61.72 & 0.054 & \mathbf{1 8 . 3} \\ \mathbf{3 3 3} & 15 & -0.853 & 23.6 & 2.32 & 7.640 & 10.124 & \mathbf{2 8 . 0} & 71.74 & 0.052 & \mathbf{2 9 . 7} \\ & 20 & -0.861 & 22.9 & 2.10 & 8.036 & 9.393 & \mathbf{3 0 . 1 8} & 78.16 & 0.049 & \mathbf{3 0 . 1 5}\end{array}$




\section{AC impedence method}

AC impedance Nyquist plots for zinc in the presence and absence of inhibitor at different temperature as shown in Fig.3. An equivalent circuit model (Fig.4.) was used to fit the Nyquist plots. The parameters such as polarization resistance $\left(R_{p}\right)$ and double capacitance values (cdl) are measured using equivalent circuit are listed in Table.1.Inhibition efficiency $\left(\eta_{z}\right)$ was calculated using the following equation.

$\eta_{\mathrm{Z}}=\frac{\mathrm{R}_{\mathrm{p}}-\mathrm{R}_{\mathrm{p}}^{\mathrm{o}}}{\mathrm{R}_{\mathrm{r}}} \times 100$

where $\mathrm{Rp}^{\circ}$ and $\mathrm{Rp}$ are the polarization resistances for uninhibited and inhibited solutions, respectively.

The depressed semicircle shows the characteristics for solid electrodes and it is referred to as frequency dispersion. This frequency dispersion is attributed to roughness and inhomogeneities [17]. According to many literatures [18, 19, 20], two models have been adopted to describe the EIS spectra for the inhomogeneous films on the metal surface of rough and porous electrodes. One is the filmed equivalent circuit model and the other is the finite transmission line model. In this work, the filmed equivalent circuit model is used to describe the inhibitor-covered metal/solutionlinterface [21]. 


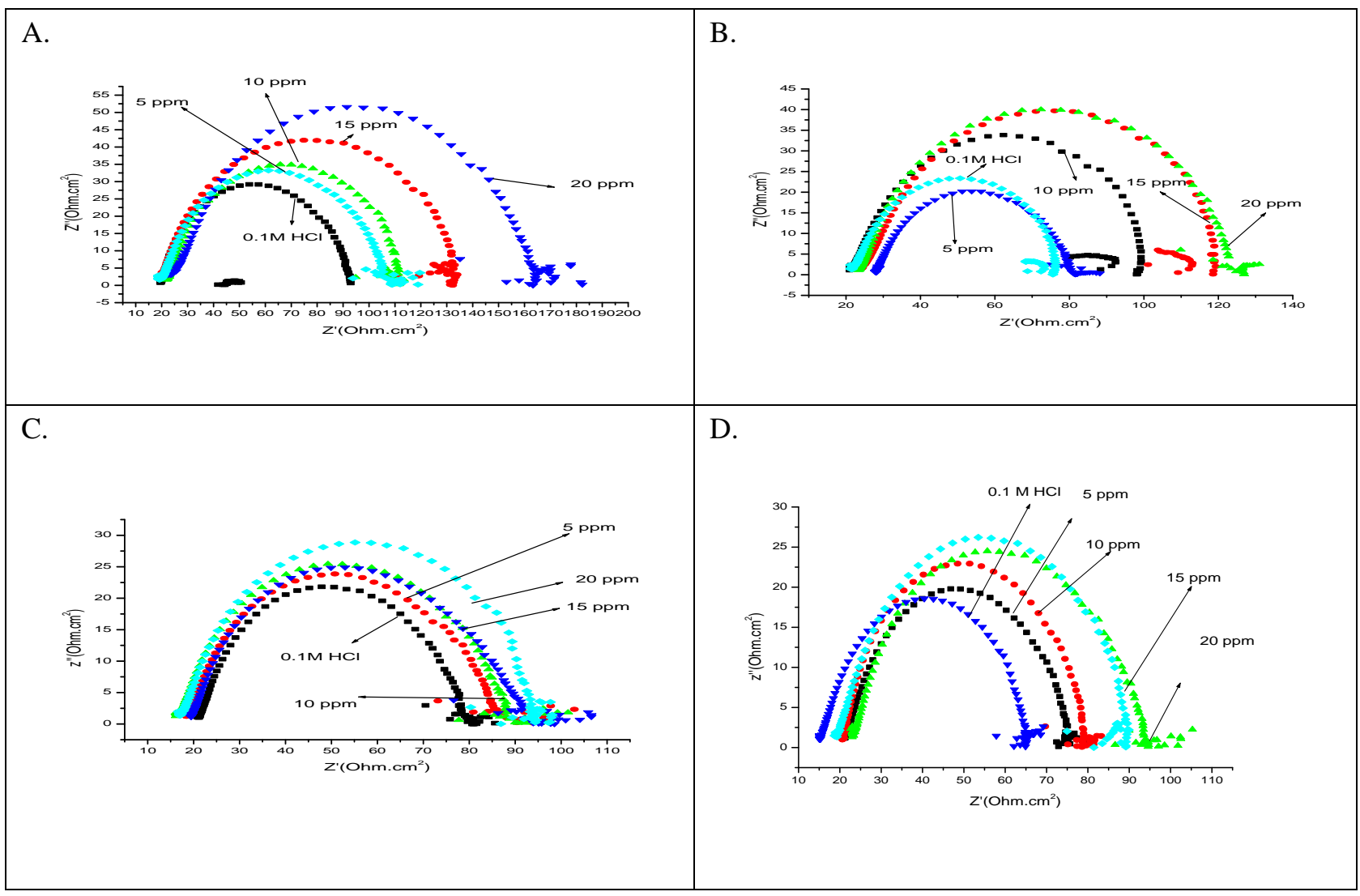

Fig.3. Nyquist Plots for zinc in $0.1 \mathrm{M} \mathrm{HCl}$ in the absence and presence of different Inhibitor concentrations at (A) $303 \mathrm{~K}$ (B) $313 \mathrm{~K}$ (C) $323 \mathrm{~K}$ (D) $333 \mathrm{~K}$ temperatures.

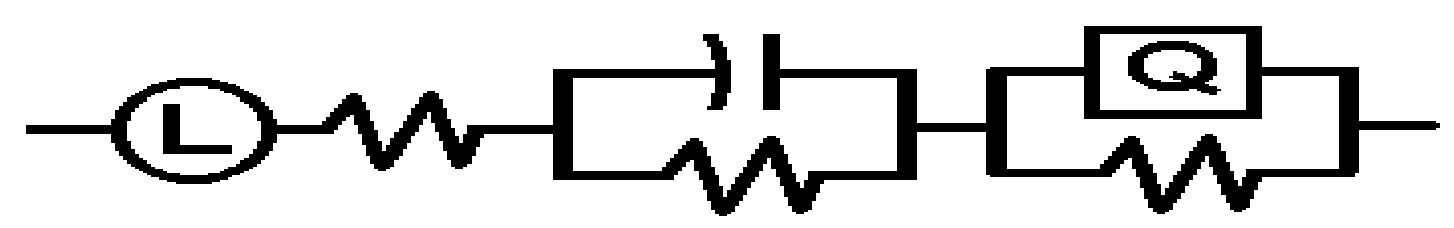

Fig.4. Electrical Equivalent circuit model used to fit impedance data

\section{Adsorption isotherm and Thermodynamic considerations}

The interaction between the inhibitor and the metal surface can be explained by the adsorption isotherm, which depends on the degree of electrode surface coverage $(\theta)$. The most frequently used isotherms are Langmuir, Frumkin, Bockris-Swinkel, El Awardy, Flory Huggins and Temkin adsorption isotherms [22].

In the present work, the investigator applied Freundlich adsorption isotherm, Temkin 
adsorption isotherm and the Langmuir adsorption isotherm at $303 \mathrm{~K}-333 \mathrm{~K}$. The plot of $\mathrm{C} / \mathrm{\theta}$ against $\mathrm{C}$ with the regression coefficient nearly equal to 1.0 which suggests the adsorption of the compound on the metal surface followed the Langmuir adsorption isotherm model at all temperatures, figure 5 .

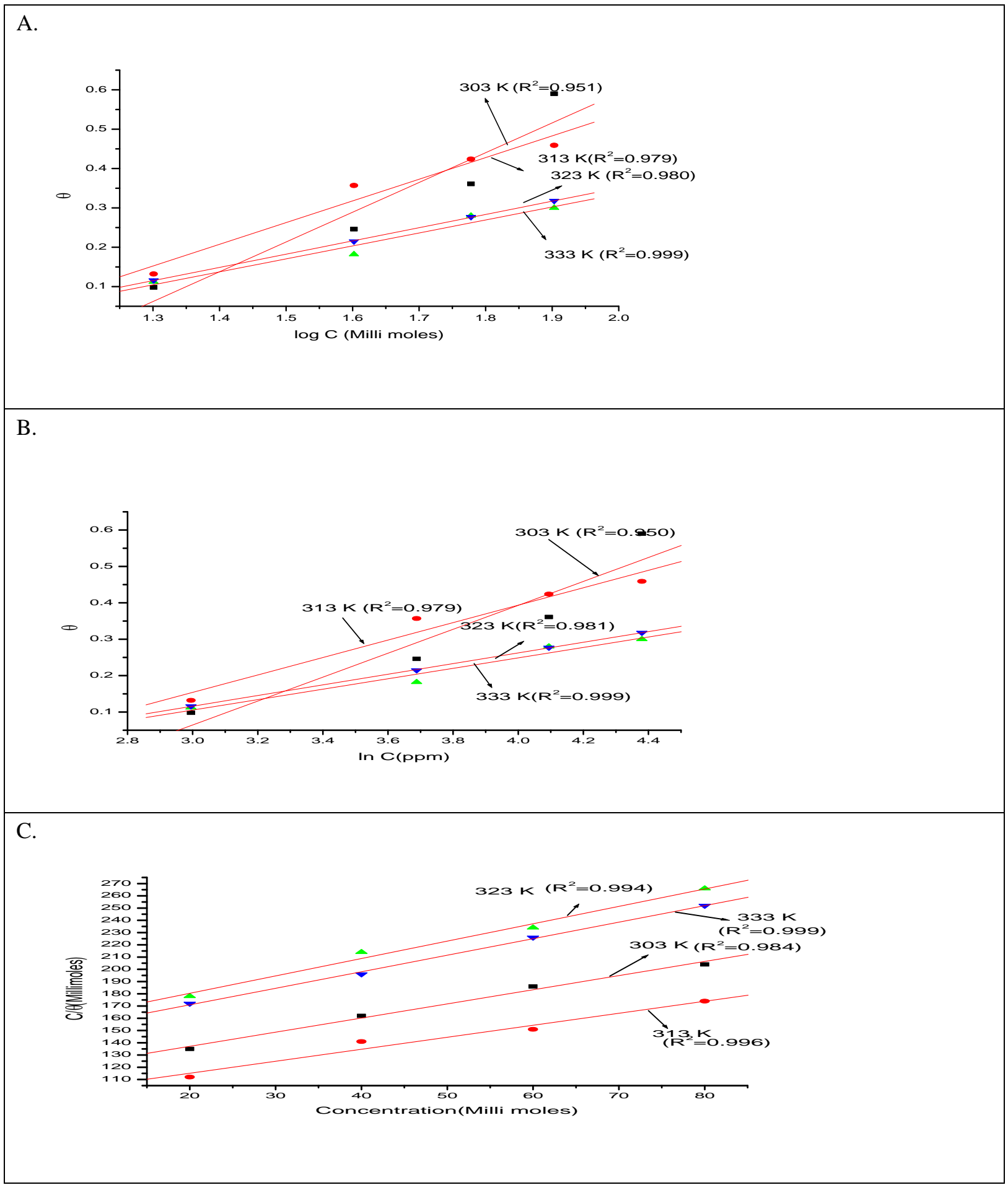

Fig.5. A) Freundlich adsorption isotherm C) Temkin adsorption isotherm B) Langmuir adsorption isotherm at $303 \mathrm{~K}-333 \mathrm{~K}$. 
Table 2. Thermodynamic Parameters for zinc in $0.1 \mathrm{M} \mathrm{HCl}$ in the absence and presence of

\begin{tabular}{ccccc}
\hline $\begin{array}{c}\text { Temperature } \\
(\mathrm{K})\end{array}$ & $\begin{array}{l}\mathrm{K}_{\mathrm{ads}} \\
\left(\mathrm{M}^{-1}\right)\end{array}$ & $\mathrm{G}^{0}{ }_{\mathrm{ads}}\left(\mathrm{kJ} \mathrm{mol}^{-1}\right)$ & $\begin{array}{c}\mathrm{H}^{0} \text { ads } \\
\left(\mathrm{kJ} \mathrm{mol}^{-1}\right)\end{array}$ & $\begin{array}{c}\mathrm{S}^{0}{ }_{\text {ads }} \\
\left(\mathrm{Jmol}^{-1} \mathrm{~K}^{-1}\right)\end{array}$ \\
\hline 303 & 259067.35 & -12.6 & -25.19 & -41.5 \\
313 & 232558.13 & -12.9 & -25.19 & -39.2 \\
323 & 18867.92 & -10.61 & -25.19 & -45.1 \\
333 & 17011.0 & -10.83 & -25.19 & -43.1 \\
\hline
\end{tabular}

different ketosulfone concentrations.

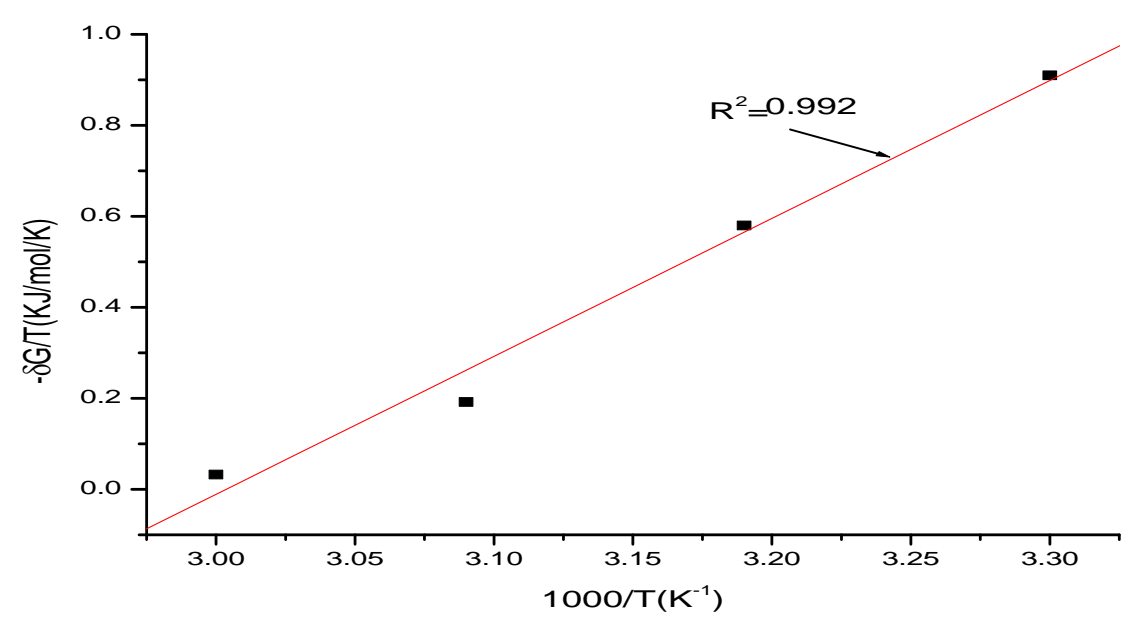

Fig.6. Relationship between $-\Delta \mathrm{G}^{0}$ ads $/ \mathrm{T}$ v/s $1000 / \mathrm{T}$

According to Langmuir adsorption isotherm, $\theta$ is related to equilibrium adsorption constant $\left(\mathrm{K}_{\mathrm{ads}}\right)$ and $\mathrm{C}$ by the equation:

$$
\frac{c}{\theta}=\frac{1}{K}+C
$$

Where $\mathrm{C}$ is the concentration of inhibitor and $\mathrm{K}$ is the equilibrium constant. The strong adsorption of inhibitor on the zinc surface obeys Langmuir's adsorption isotherm. The $K_{\text {ads }}$ values were calculated from straight line intercept obtained from the plot of $\mathrm{C} / \theta$ versus $\mathrm{C}$. This is related to the standard free energy of adsorption ( $\mathrm{G}^{0}$ ads) with the following equation. 


$$
\mathrm{K}_{\mathrm{ads}}=\frac{1}{5.5 .5} \exp \left(-\Delta \mathrm{G}^{0}{ }_{\mathrm{ads}} / \mathrm{RT}\right)
$$

The gas constant is donated by $\mathrm{R}$ and absolute temperature is donated by $\mathrm{T}$. The obtained results ( $K_{\text {ads }}$ and- $\Delta \mathrm{G}^{0}$ ads $)$ are depicted in the Table.2.

The $\Delta \mathrm{H}^{0}$ ads and $\Delta \mathrm{S}_{\text {ads }}^{0}$ are also calculated from the Gibbs-Helmholtz equation. The Gibbs-Helmoltz equation can be written as [23],

$$
\left\{\partial\left(\Delta G_{a d s}^{0} / T\right) \mid \partial T\right\} \mathrm{p}=\frac{-\Delta H_{a d s}^{0}}{T^{2}}
$$

By integrating the above equation, we get

$$
\frac{\Delta \mathrm{G}_{2 \mathrm{ds}}^{0}}{\mathbf{T}}=\frac{\Delta \mathrm{H}_{2 \mathrm{ds}}^{\mathrm{Q}}}{\mathbf{T}}+\mathbf{K}
$$

The relationship between $\Delta \mathrm{G}^{0}$ ads $/ \mathrm{T}$ V/S 1000/T depicted in Fig.6, with the slope equal to the $\Delta \mathrm{H}^{0}$ ads and $\Delta \mathrm{S}^{0}$ ads is the intercept. $\Delta \mathrm{H}^{0}$ ads and $\Delta \mathrm{S}_{\text {ads }}^{0}$ are reported in the table 2.

In the present study the $\Delta \mathrm{G}_{\text {ads }}^{0}$ carries a negative sign which indicates that the adsorption process occurs spontaneously and explains the adsorbed layer of inhibitor on the metal surface is stable [24].The Many literatures reported physisorption, when the magnitude of $\mathrm{G}^{0}$ ads around $-20 \mathrm{KJ} / \mathrm{mol}$ or less and those approaches to $-40 \mathrm{~kJ} / \mathrm{mol}$ are indicative of chemisorption. In the present study investigator obtained the maximum value of $-12.8 \mathrm{KJ} / \mathrm{Mol}$ and it is concluded that the inhibitor adsorption on the metal surface follows physiorption [25].

\section{Activation parameters:}

The rate of corrosion increases with increase in the temperature. The effect of temperature on the mechanism of corrosion and corrosion inhibition can be explained by the activation parameters. The effect of temperature on corrosion and corrosion inhibition is studied using Arrhenius equation and Transition state plots [26].

The Arrhenius equation can be written as,

$$
\ln v_{\text {corr }}=\ln \mathrm{A}-\mathrm{Ea}^{*} / \mathrm{RT}
$$

Where $v_{\text {corr }}$ is the corrosion rate, $\mathrm{Ea} *$ is the apparent activation energy $(\mathrm{J} / \mathrm{mol}), R$ is the gas 
constant $(8.314 \mathrm{~J} / \mathrm{mol} / \mathrm{K}), \mathrm{T}$ is the absolute temperature $(\mathrm{K})$ and $\mathrm{A}$ is the Arrehenius pre-exponential factor.Fig.7 presents the Arrhenius plot of $\ln \boldsymbol{v}_{\text {corr }}$ against 1/T for the corrosion of mild steel in $1 \mathrm{M} \mathrm{HCl}$ solution in the presence and absence of inhibitor From Fig.6, the slope $\left(-\mathrm{E}_{\mathrm{a}}^{*} / \mathrm{R}\right)$ of each individual straight line was determined and the apparent activation energy $\left(E_{\mathrm{a}}{ }^{*}\right)$ was calculated using the expression $\quad E_{a}{ }^{*}=$ slope $\times R(8.314 \mathrm{~J} / \mathrm{mol} / \mathrm{K})$. The calculated apparent activation energy $\left(\mathrm{E}_{\mathrm{a}}^{*}\right)$ values and Arrehenius pre-exponential factors can be reported in table 3 .

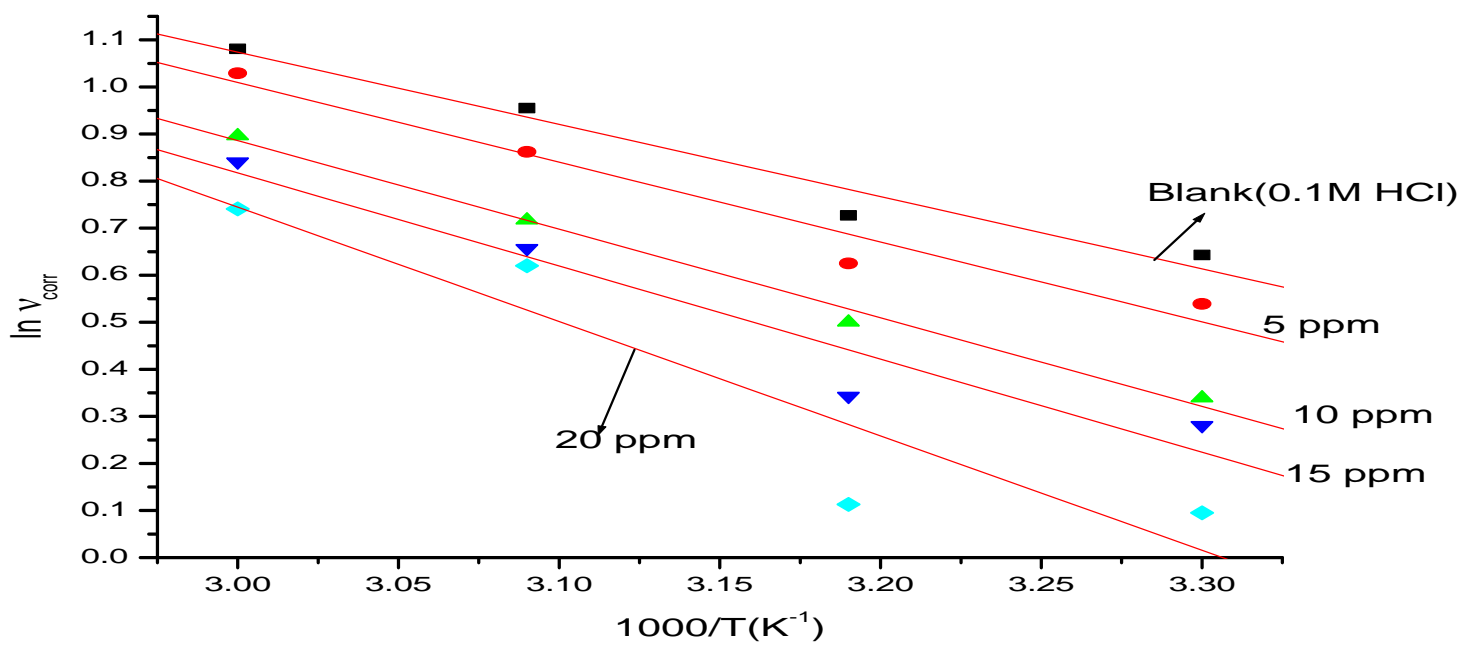

Fig.7. Arrehnious plot 


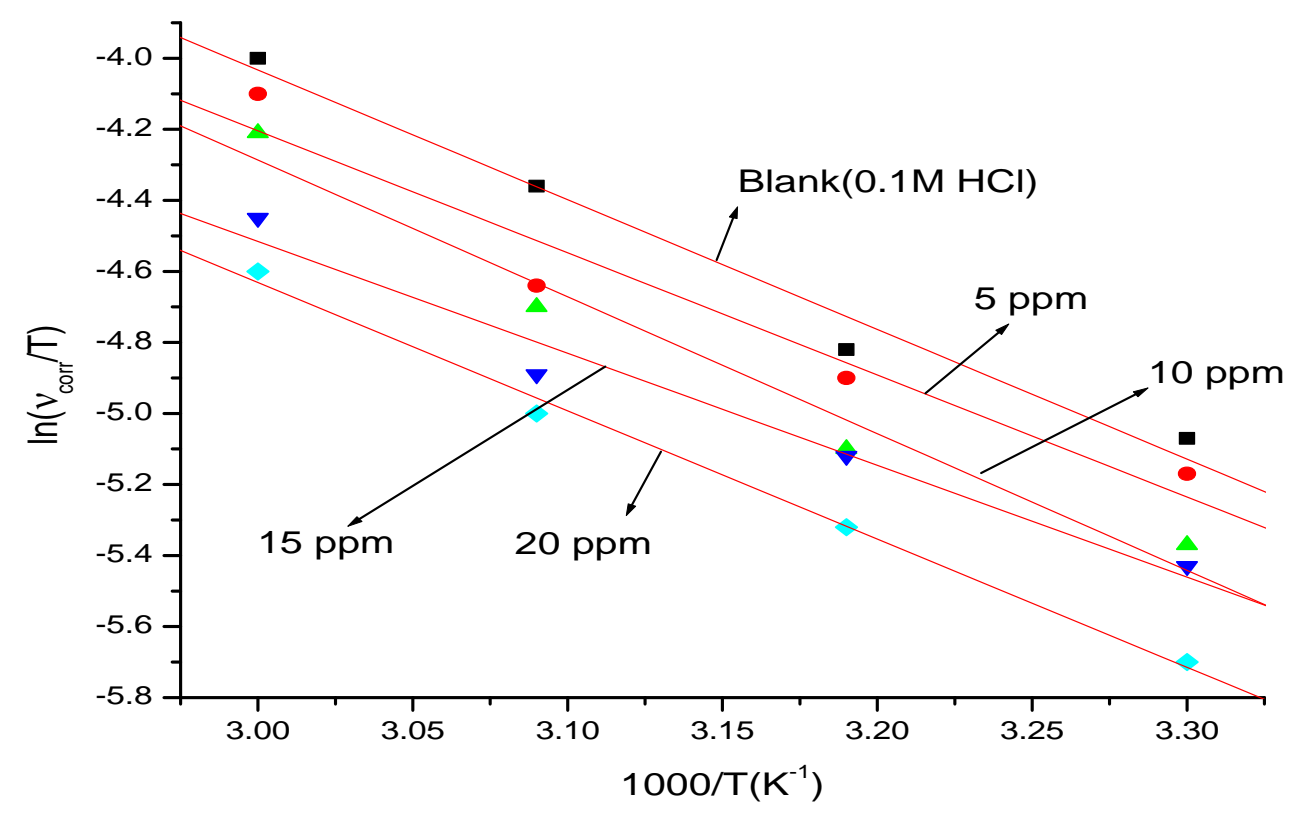

Fig.8. Transition plot

Table 3. Activation Parameters for zinc in $0.1 \mathrm{M} \mathrm{HCl}$ in the absence and presence of different ketosulfone concentrations.

\begin{tabular}{ccccc}
\hline $\begin{array}{c}\text { Concentration of } \\
\text { Inhibitor(ppm) }\end{array}$ & $\begin{array}{c}\mathrm{Ea} \\
(\mathrm{kJ} / \mathrm{mol})\end{array}$ & $\begin{array}{c}\mathrm{A} \\
\left(\mathrm{kJ} \mathrm{mol}^{-1}\right)\end{array}$ & $\begin{array}{c}\mathrm{H}^{*} \\
\left(\mathrm{~kJ} \mathrm{~mol}^{-1}\right)\end{array}$ & $\begin{array}{c}\mathrm{S}^{*} \\
\left(\mathrm{~J} \mathrm{~mol}^{-1} \mathrm{~K}^{-1}\right)\end{array}$ \\
\hline Blank & 12.75 & 270.42 & -26.1 & -16.5 \\
5 & 14.00 & 441.42 & -28.5 & -16.83 \\
10 & 15.63 & 685.39 & -30.0 & -17.55 \\
15 & 16.43 & 854.05 & -30.3 & -17.68 \\
20 & 20.11 & 3084.3 & -32.0 & -18.82 \\
\hline
\end{tabular}

The values of the standard enthalpy $\left(\mathrm{H}^{*}\right)$ and standard entropy $\left(\mathrm{S}^{*}\right)$ of activation were calculated by the following equation [27]

$$
\left.\frac{\ln v e o r r}{T}=\left[\ln \frac{R}{N h}+\frac{\Delta S^{*}}{R}\right]-\frac{\Delta H^{*}}{R}\right]
$$

Where $h$ is plank's constant $\left(6.626 \times 10^{-34} \mathrm{~m}^{2} . \mathrm{kg} / \mathrm{s}\right)$ and Avogadro's number $\left(6.022 \times 10^{23}\right)$.

A Transition plot of $\ln \left(v_{\text {corr }} / \mathrm{T}\right) \mathrm{Vs} 1 / \mathrm{T}$ gave straight lines (Fig.8) and are depicted in Table.3. 
$\mathrm{H}^{*}$ value calculated by using slope with an expression. $\quad \mathrm{H}^{*}=-$ slope $\times \mathrm{R}(8.314)$ and $\mathrm{S}$ * calculated by the help of intercept with an expression $S^{*}=$ intercept $-\ln \frac{R}{N h}$. The calculated values of $\mathrm{H}^{*}$ and $\mathrm{S}^{*}$ are listed in Table 3.

The inhibition efficiency of Ketosulfone decreases with temperature and this results in the increase in the apparent activation corrosion energy. This trend probably was attributed to physiorption of Ketosulfone on the zinc surface [28].

The positive signs of enthalpies $\left(\mathrm{H}^{*}\right)$ show that the dissolution process is endothermic in nature. The shift towards positive value of entropies $\left(\mathrm{S}^{*}\right)$ implies that the increasing in the disorderliness of reactants to the activated complex [29, 30].

\section{Scanning Electron spectroscopy}

The surface appearance of the zinc in $0.1 \mathrm{M} \mathrm{HCl}$ solution in the absence and in the presence of ketosulfone inhibitor by using Scanning Electron Microscopy (SEM) are shown in figure 9. When a smooth surface of zinc is immersed in $0.1 \mathrm{M} \mathrm{HCl}$ for $8 \mathrm{hrs}$, A corroded surface is observed in the SEM image. However, in the presence of inhibitor, the surface improved markedly in terms of smoothness. Usually a protective film coated on the mild steel surface, which proceeds to a considerable reduction of the corrosion process.

A.

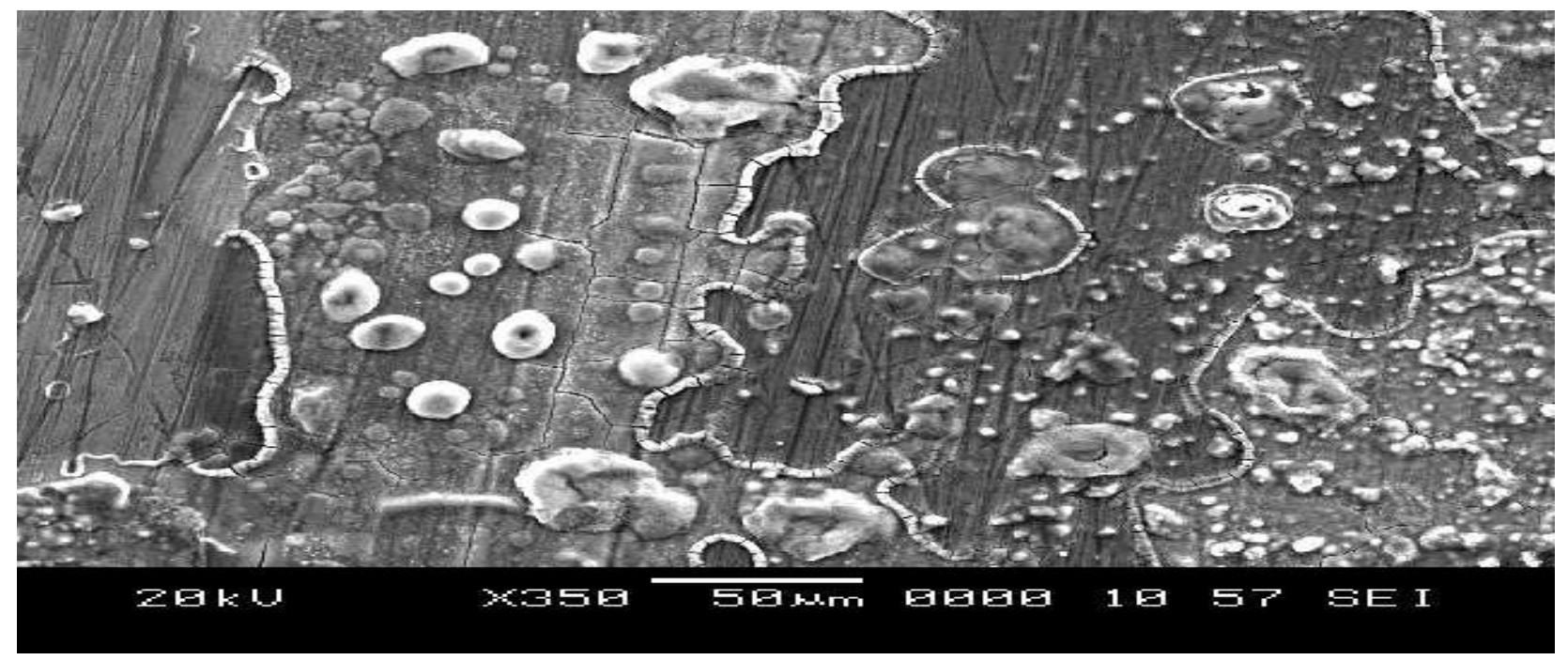

B. 


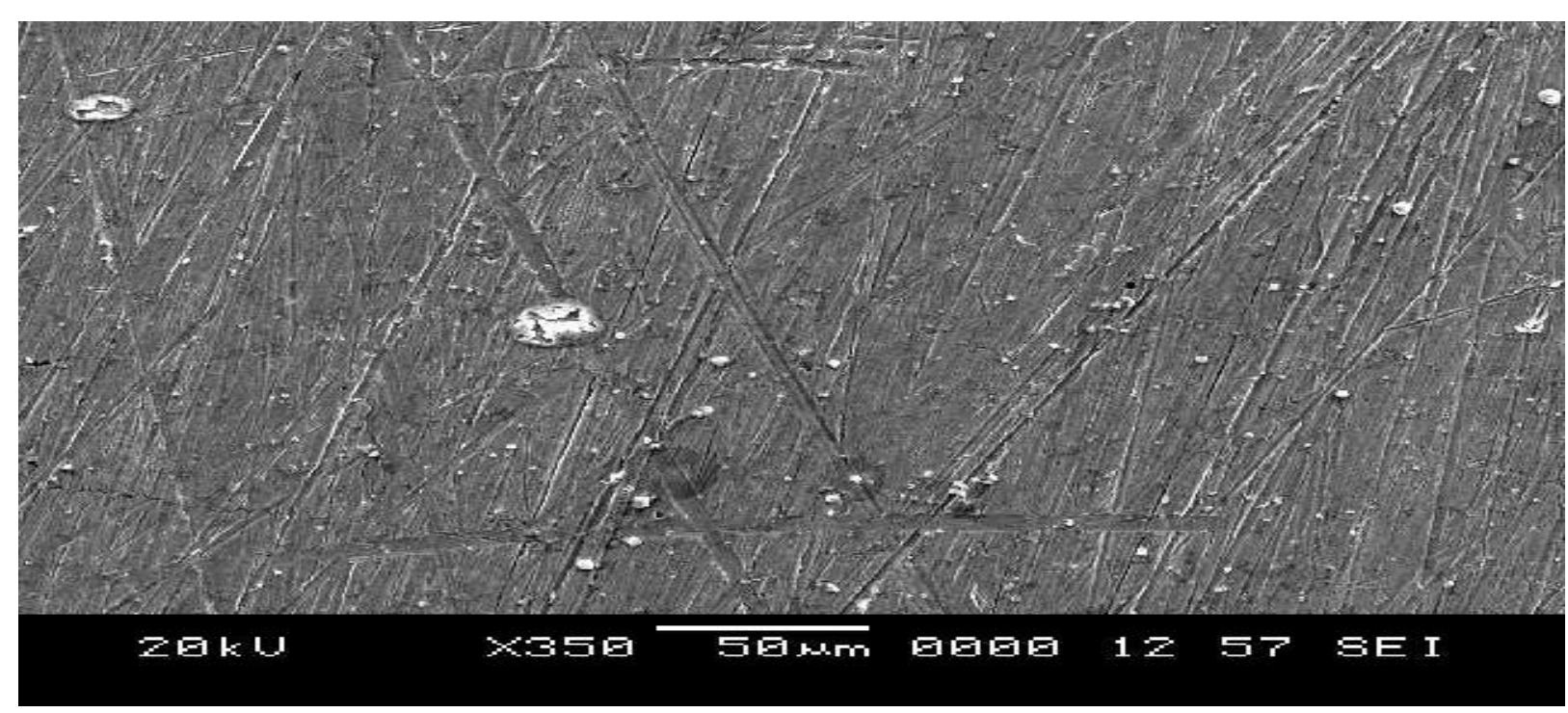

Fig.9. SEM images of zinc in $0.1 \mathrm{M} \mathrm{HCl}$ solution at $303 \mathrm{~K}$ : (A) In absence of inhibitor (B) in presence of inhibitor.

\section{Experimental}

\section{Material}

The corrosion inhibition studies were carried out for Zinc samples of pure grade $(\mathrm{Cu} 0.17 \%$, Ti $0.075 \%$, Al $<0.05 \%, \mathrm{~Pb}-\mathrm{Cd}<0.003 \%$, Fe 0.002\%, Sn 0.001\%and Mg 0.0005\% remaining is $\mathrm{Zn})$. Electrochemical measurements carried out for the strips with an exposed area of $1 \mathrm{~cm}^{2}$. The samples were polished by emery paper (Grade No.: 80-1500), washed thoroughly with distilled water.

\section{Methodology}

Tafel Polarization method and AC-impedance method

The Ivium electrochemical analyzer is used to carry out the Tafel Polarization method and AC-impedance method at 303-333K. The cell consists of working electrode (zinc), indicator electrode (PT electrode) and secondary reference electrode (Calomel electrode). Before each electrochemical measurement, steady state open circuit potential (OCP) is noted down.

In Tafel Polarization measurements, Tafel curves (Log current Vs Potential) were recorded at a scan rate of $0.001 \mathrm{~V} \mathrm{~s}^{-1}$ in the potential range of -0.2 and $+0.2 \mathrm{~V}$.

In AC-Impedance measurements, Nyquist plots were recorded at the amplitude of $5 \mathrm{mV}$ in the 
frequency range from $100 \mathrm{KHz}$ to $10 \mathrm{MHz}$. An appropriate equivalent circuit is used to fit the Nyquist plots by using Z-Simp Win 3.21 software.

\section{Adsorption Isotherm and thermodynamic parameters:}

The mode of adsorption of Ketosulfone on zinc in $0.1 \mathrm{M} \mathrm{HCl}$ at different temperature studied by adsorption isotherms like Freundlich adsorption isotherm, Temkin adsorption isotherm and Langmuir adsorption isotherm at 303K -333K. Thermodynamic parameters were calculated by using graphs.

\section{Scanning electron microscopic (SEM) studies}

Zinc strip with dimensions of $1.0 \mathrm{~cm}$ x $1.0 \mathrm{~cm}$ x $0.1 \mathrm{~cm}$ were abraded with emery papers from grade no. 80 up to 1200 , cleaned with double distilled water, rinsed with acetone and dried at room temperature. After immersion in $0.1 \mathrm{M} \mathrm{HCl}$ in the absence and presence of the optimum concentration of inhibitor at $25^{\circ} \mathrm{C}$ temperature for 4 hours. The zinc strip was again rinsed with distilled water and acetone dried at room temperature. Then SEM images were recorded using the JEOL JSM-840A model. The energy of the accelerating beam employed was $20 \mathrm{~V}$.

\section{Conclusions}

- There is a good agreement between polarization method and Ac-impedance method at 303-333K.

- The maximum \% I.E. of Ketosulfone for the zinc metal in acidic media is $59.09 \%$.

- $\%$ I.E. deceases after $313 \mathrm{~K}$.

- Tafel plots reveal the Ketosulfone is a mixed type inhibitor.

- Adsorption of the inhibitor follows the Langmuir isotherm.

- The interaction of inhibitor on the zinc surface takes place through physical adsorption.

- Activation parameters explain the corrosion process.

- A small amount of inhibitor shows inhibition efficiency.

\section{Acknowledgements}

The authors are thankful to the higher authorities of SSE, Mangalore, Karnataka, India, for providing the research lab. Authors are also grateful to AICTE, New Delhi, Govt. of India 
under MODROBS scheme [Ref. No 8024/RIFD/MOD 292 /2010-11 dated 31-03-2011for providing instrumental facility.

\section{REFERENCES}

[1] Braun R, Lopez E, Vollmer, D. Low molecular weight straight chain amines as corrosion inhibitors. Corros Sci. 34, 1993, 1251-1257.

[2] Praveen BM, Venkatesha TV,Arthoba Naik Y, Prashantha K Corrosion studies of carbon nanotubes-Zn composite coating. Surface and Coatings Technology.201, 2007, 5836-5842.

[3] Praveen BM, Venkatesha TV. Electrodeposition and properties of $\mathrm{Zn}-\mathrm{Ni}-\mathrm{CNT}$ composite coatings. Journal of Alloys and Compounds. 482, 2009, 53-57.

[4] Praveen BM, Venkatesha TV, Naik YA, Prashantha K. Corrosion Behavior of Zn-TiO2 Composite Coating. Synthesis and Reactivity in Inorganic, Metal-Organic, and Nano-Metal Chemistry. 37, 2007, 461-465.

[5] Shylesha BS, Venkatesha TV, Praveen BM. New Electroactive compounds as corrosion inhibitors for zinc in acidic medium. Adv. Appl. Sci. Res. 2, 2011, 333-341.

[6] Sachin HP, Praveen BM, Abd Hamid SB. Corrosion Inhibition of Zinc by a New Inhibitor in Hydrochloric Acid Medium. Research Journal of Chemical Science.3, 2013, 82-89.

[7] Hebbar N, Praveen BM, Prasanna BM, Venkatesha VT. Inhibition Effect of an Anti-HIV Drug on the Corrosion of Zinc in Acidic Medium. Transactions of the Indian Institute of Metals. 2014/ DOI 10.1007/s12666-014-0484-6.

[8] Shylesha B, Venkatesha TV, Praveen BM. Ziprasidone as a corrosion inhibitor for zinc in different acid medium. J. Chem. Pharm. Res. 3, 2011, 501-507.

[9] Hari Kumar IS, Karthikeyan S.Inhibition of mild steel corrosion in hydrochloric acid solution by cloxacillin drug. J.Mater. Environ. Sci. 3, 2012, 925-934. 
[10] Matad PB, Mokshanatha PB, Hebbar N, Venkatesha VT, Tandon, HC. Ketosulfone Drug as a Green Corrosion Inhibitor for Mild Steel in Acidic Medium. Ind. Eng. Chem. Res.53, $2014,8436-8444$.

[11] Application Note CORR-1Princeton Applied Research, 801 S. Illinois Avenue, Oak Ridge, TN 37830.

[12] Stern M .A method for determining corrosion rates from linear polarization data. Corrosion. 14, 2014) 440-444.

[13] Aprael S Yaro, Anees, A, Khadom. The Effect of Uncompensated IR-Drop on Polarization Resistance Measurements

[14] Negm NA, Ghuiba FM, Tawfik SM. Novelisoxazolium cationic Schiff base compounds as corrosion inhibitors for carbon steel in hydrochloric acid. J. Corros Sci. 53: 566-575.

[15] Harshida G, Chaudhari Mahendrasinh, Mahida M Aliphatic amines as corrosion inhibitors for zinc in hydrochloric acid. Der Pharma Chemica. 4, 2012, 2305-2312.

[16] Shafaa M, Lahmod Kinetics of the corrosion inhibition reaction of steel alloys in acidic media by potassium iodide.Reac Kinet Mech Cat.2013/DOI 10.1007/s11144-013-0568-z.

[17] Sobhi M. Marjoram Extract as Corrosion Inhibitor for Dissolution of Zinc in 1.0M HCl. International Journal of Corrosion. Article ID 763476, 2013, 7 pages.

[18] Tang Y, Yang X, Yang W, Chen Y,Wan R.Experimental and Molecular Dynamics Studies on Corrosion Inhibition of Mild Steel by 2-Amino-5-Phenyl-1,3,4- Thia-Diazole. Corrosion Science. 2, 2010, 242-249.

[19] Kelly RG, Scully J, Shoesmith RDW, Buchheit RG. Electrochemical Techniques in Corrosion Science and Engineering. Marcel Dekker Inc. New York (2002). 
[20] Pengju Liu, Xia Fang, Yongming Tang, Chunning Sun, Cheng Yao. Electrochemical and Quantum Chemical Studies of 5-Substituted Tetrazoles as Corrosion Inhibitors for Copper in Aerated 0.5 M H2SO4 Solution. Materials Sciences and Applications. 2, 2011, 1268-1278.

[21]BouhriraK, Chetouani A, Zerouali D, Hammouti B, Yahyi A, Et-Touhami A, Yahyaoui R, Touzani R. Theoretical investigation of inhibition of the corrosion of A106 steel in $\mathrm{NaCl}$ solution by di-n-butyl bis(thiophene-2-carboxylato-O,O0)tin(IV), Research on Chemical Intermediates. 40, 2011, 569-586.

[22] Okafor PC, Osabor V, Ebenso EE.Ecofriendly corrosion inhibitors: inhibitive action of ethanol extracts of Garcinia kola for the corrosion of aluminum in acidic medium. Pigment Resin Technology. 36, 2007, 299-305.

[23] Noor EA. Temperature Effects on the Corrosion Inhibition of Mild Steel in Acidic Solutions by Aqueous Extract of Fenugreek Leave. Int. J. Electrochem. Sci.2, 2007, 996-1017. [24] Eno Ebenso E, Ime Obot B. Inhibitive Properties, Thermodynamic Characterization and Quantum Chemical Studies of Secnidazole on Mild Steel Corrosion in Acidic Medium. Int. J. Electrochem. Sci. 5, 2010, 2012 - 2035.

[25] Moretti G, Guidi F, Grion G. Tryptamine as a green iron corrosion inhibitor in $0.5 \mathrm{M}$ dearated sulphuric acid.Corros. Sci. 46, 2004, 387-403.

[26] Abdallah M. Antibacterial drugs as corrosion inhibition for corrosion of $\mathrm{Al}$ in $\mathrm{HCl}$ solution.Corros. Sci. 46, 2004, 1981-1996.

[27] Fouda AS, Al-Sarawy AA, Sh Ahmed F, El-Abbasy HM. Corrosion inhibition of aluminium 6063 using some pharmaceutical compounds.Corros. Sci. 51, 2009, 485-492.

[28] Martinez S, Stern I. Thermodynamic characterization of metal dissolution and inhibitor 
adsorption processes in the low carbon steel/mimosa tannin/sulfuric acid system. Appl.Surf.

Sci. 199, 2001, 83-89.

How to cite this article

Narayana Hebbar, Praveen B M, Prasanna B M, Venkatarangaiah T. Venkatesha. Corrosion inhibition behavior of ketosulfone for zinc in acidic medium. J Fundam Appl Sci. 2015, 7(2), 271-289. 